\title{
Caries dental: de la placa ecológica a las decisiones clínicas*
}

\author{
Dental Caries: from Ecological Plaque to Clinical Decisions
}

Cárie dentária: da placa ecológica às decisões clínicas

Fecha de recepción: 19-02/2020 | Fecha de aceptación: 10-08-2020

\begin{abstract}
Gloria Cristina Moreno Abello
Pontificia Universidad Javeriana Bogotá, Colombia. gcmoreno@javeriana.edu.co. https://orcid.org/0000-0002-5597-5871
\end{abstract}

\section{Laura Catalina lara HernándeZ}

Pontificia Universidad Javeriana Bogotá, Colombia. lara-1@javeriana.edu.co. https://orcid.org/0000-0002-2613-4483

*Revisión integrativa

Correspondencia: gcmoreno@javeriana.edu.co; lara-1@javeriana.edu.co.

doi: https://doi.org/10.11144/Javeriana.uo39.cdpe 
Cómo citar: Moreno Abello GC, Lara Hernández LC. Caries dental: de la placa ecológica a las decisiones clínicas. Univ Odontol. 2020; 39. https://doi.org/10.11144/Javeriana.uo39.cdpe

\section{RESUMEN}

Antecedentes: la caries dental ha sido estudiada desde múltiples enfoques, sin embargo, a pesar del conocimiento disponible, lograr medidas efectivas para prevenir su aparición en los individuos y las comunidades, aún parece lejano. Objetivo: integrar los cambios conceptuales actualmente aceptados para caries, con escenarios en la práctica clínica, para apoyar a los profesionales en las decisiones terapéuticas. Método: en esta revisión integrativa se consultaron PubMed, Cochrane, Science Direct, SciELO, EBSCO utilizando como palabras claves: dental caries, model, prevention, ICDAS, risk factors, risk assessment. se verificó que el objetivo de cada fuente permitiera hacer el recorrido histórico del concepto de caries identificando aspectos centrales, relacionándolos con las limitaciones para que la teoría se evidencie en la práctica clínica. Resultados: la síntesis de la literatura se presenta organizada en: evolución de la definición de la caries dental a partir del papel de las bacterias y su impacto en las decisiones clínicas, acciones para abarcar la definición actual de caries dental y acciones ajustadas al modelo ICCMS para llevarlo a la práctica. Conclusión: los cambios conceptuales en caries dental se reflejan en los diagnósticos actuales y abordajes multivariados que aun requieren fortalecer el análisis y un control efectivo de los factores de riesgo, buscando un cuidado centrado en la persona, basado en la relación entre el comportamiento de los individuos a lo largo de la vida y la dinámica de la patología, que invitan al profesional a fortalecer un abordaje preventivo para controlar la enfermedad y evitar sus secuelas discapacitantes. 


\section{Palabras clave}

caries dental; CariesCare; cariología; dieta cariogénica; factores de riesgo; International Caries Detection and Assessment System (ICDAS); ICDAS; odontología; prevención de la enfermedad; riesgo de caries; salud oral; terapia

\section{ABSTRACT}

Background: Dental caries has been studied from multiple perspectives, however, despite the available knowledge, achieving effective measures to prevent its appearance in individuals and communities still seems distant. Purpose: to integrate the conceptual changes in the currently accepted understanding of caries, with scenarios in clinical practice, to support professionals in therapeutic decisions. Method: In this integrative review, PubMed, Cochrane, Science Direct, SciELO, EBSCO were consulted using as keywords: dental caries, model, prevention, ICDAS, risk factors and risk assessment. The objective of each source was verified to allow making the historical journey of the caries concept by identifying central aspects, relating them to the limitations that make the theory not evident in clinical practice. Results: the synthesis of the literature is presented and organized in: evolution of the definition of dental caries from the role of bacteria and its impact on clinical decisions, actions to cover the current definition of dental caries and actions adjusted to the ICCMS model to put into practice. Conclusion: the conceptual changes in dental caries are reflected in current diagnoses and multivariate approaches that are still required to strengthen the analysis and the effective control of risk factors, seeking care centered on the person, based on the relationship between the behavior of the individuals throughout their 
life and the dynamics of the pathology, which invite the professional to strengthen a preventative approach to control the disease and avoid its disabling sequelae.

\section{Keywords}

CariesCare; cariogenic diet; cariology; dental caries; dentistry; disease prevention; International Caries Detection and Assessment System (ICDAS); ICDAS; oral health; risk assessment; risk factors; therapy

\section{RESUMO}

Antecedentes: A cárie dentária tem sido estudada sob múltiplas perspectivas, no entanto, apesar do conhecimento disponível, alcançar medidas efetivas para impedir seu aparecimento em indivíduos e comunidades ainda parece distante. Objetivo: Integrar as mudanças conceituais aceitas atualmente no entendimento da cárie, com cenários na prática clínica, para apoiar os profissionais nas decisões terapêuticas. Método: Nesta revisão integrativa, foram consultadas as bases de dados PubMed, Cochrane, Science Direct, SciELO, EBSCO, utilizando como palavraschave: cárie dentária, modelo, prevenção, ICDAS, fatores de risco, avaliação de risco. Verificouse que o objetivo de cada fonte permitiu realizar a trajetória histórica do conceito da cárie identificando aspectos centrais, relacionando-os às limitações para que a teoria seja evidente na prática clínica. Resultados: a síntese da literatura é apresentada organizada para: evolução da definição de cárie dentária a partir do papel das bactérias e seu impacto nas decisões clínicas, as ações para cobrir a definição atual da cárie dentária e as ações ajustadas ao modelo ICCMS para colocá-lo em prática. Conclusão: as mudanças conceituais na cárie dentária se refletem nos 
diagnósticos atuais e nas abordagens multivariadas que ainda exigem o fortalecimento da análise e controle efetivo dos fatores de risco, buscando um atendimento centrado na pessoa, com base na relação entre o comportamento dos indivíduos ao longo da vida e a dinâmica da patologia, que convidam o profissional a fortalecer uma abordagem preventiva para controlar a doença e evitar sequelas incapacitantes.

\section{Palavras-chave}

CariesCare; cariologia; dieta cariogênica; fatores de risco; odontologia; prevenção de doença; risco de cárie; Sistema Internacional de Detecção e Avaliação de Cárie (ICDAS); ICDAS; saúde bucal; terapia

\section{INTRODUCCIÓN}

Cuando se revisa la patogénesis de la caries, las bacterias siempre han estado presentes, y en consecuencia las definiciones de la patología siempre las incluyen, pero en la medida en la que avanza el conocimiento en microbiología, la presencia y virulencia de las bacterias no explican completamente la enfermedad. En consecuencia, se han requerido aproximaciones más complejas para entender la patogénesis de la caries dental, generando la construcción de modelos multivariados para controlar esta patología en diferentes escenarios. En estos modelos participan variables biológicas, psicológicas y sociales, que incluyen desde un individuo hasta medidas de política pública, lo que hace que deban interpretarse ligadas al contexto social con rigurosidad $(1,2)$.

En este punto, podría pensarse que la gran cantidad de evidencia aportada por las ciencias básicas, las ciencias básicas aplicadas, la clínica, la salud pública y las ciencias sociales y del 
comportamiento a la odontología, permitirían aproximar los modelos teóricos a la práctica clínica, esto sin duda implica (3), como concluye Bordoni (1) que hay que mejorar la formación del recurso humano en el traslado de la investigación a la toma de medidas clínicas y sanitarias efectivas, especialmente aquellas tendientes a la equidad.

La caries dental se clasifica dentro de las enfermedades bucodentales no transmisibles, como la patología más prevalente en dientes permanentes, y hace parte de las enfermedades que afectan a las personas durante toda la vida $(4,5)$. En general su tratamiento con abordajes tradicionales es costoso, y la capacidad de atención en varios sistemas de salud en el mundo, dificultan que los pacientes sean atendidos, generando secuelas como el edentulismo parcial o total que, a su vez, es una de las diez causas de años de vida perdidos por discapacidad, tanto en países con altos ingresos, como en Colombia porque limitan la capacidad de una persona para morder, masticar, sonreír y hablar, además de su bienestar psicosocial $(1,6,7)$.

Esta revisión integrativa sintetiza información importante para entender la caries dental desde un abordaje actual y pretende mejorar la adherencia de los odontólogos a este manejo de la patología, al facilitar el entendimiento actual de la enfermedad, identificando aplicaciones del conocimiento disponible, útiles en el abordaje del paciente con caries, dentro de una práctica clínica que debe ajustarse a las necesidades de salud pública de los países, las comunidades y los individuos, desde la formación y actualización del talento humano en salud oral.

Considerando que las acciones de los diversos actores involucrados en el manejo de la caries no han logrado prevenir y controlar la enfermedad y no integran el conocimiento disponible en 
diferentes áreas del conocimiento a su quehacer profesional, el objetivo de esta revisión es integrar los elementos fundamentales de los cambios conceptuales para relacionarlos paso a paso con la práctica clínica, con la finalidad de facilitar la aproximación de los profesionales a la toma de decisiones terapéuticas.

\section{MATERIALES Y MÉTODOS}

Para realizar esta esta revisión integrativa (8), se hizo una búsqueda en diferentes bases de datos como lo son PubMed, Cochrane, Science Direct, SciELO y EBSCO. Se emplearon como palabras claves: dental caries, model, prevention, ICDAS, risk factors, risk assessment, cariogenic diet. Se realizó una primera lectura verificando que el objetivo de las referencias relevantes permitiera hacer el recorrido histórico del concepto de caries ajustando, adecuado y evaluando las palabras claves de la búsqueda. Las referencias seleccionadas permitieron identificar aspectos centrales en la evolución del entendimiento de la caries dental que se podían relacionar con las limitaciones para que la teoría se reflejara en la práctica clínica. Se incluyeron referencias publicadas en inglés y español.

\section{RESULTADOS Y DISCUSIÓN}

Evolución de la definición de la caries dental a partir del papel de las bacterias y su impacto en las decisiones clínicas

Para la OMS "la caries dental se produce cuando la placa bacteriana que se forma en la superficie del diente convierte los azúcares libres contenidos en alimentos y bebidas en ácidos, que con el 
tiempo disuelven el esmalte dental y la dentina. La ingesta abundante y continua de azúcares libres, la exposición insuficiente al flúor y la falta de remoción periódica de la placa bacteriana provocan la ruptura de las estructuras dentarias, lo que propicia el desarrollo de caries y dolor, menoscaba la calidad de vida en lo que respecta a la salud bucal y, en una etapa avanzada, ocasiona pérdida de dientes e infección sistémica" (4).

Hay que resaltar que la caries se considera en gran medida prevenible o tratable desde sus etapas iniciales, para evitar grandes pérdidas de la estructura dental o incluso dientes. En el 2016 se estimó que, en todo el mundo, unos 2400 millones de personas tenían caries en dientes permanentes, y 486 millones de niños tenían caries en los dientes temporales (4). En este punto, el trabajo entonces es prevenir lo prevenible, apoyados en la comprensión de la patogénesis de la enfermedad y la evidencia científica disponible, para soportar la toma de decisiones clínicas dirigidas a evitar y controlar la enfermedad a bajo costo para los pacientes, lo que a su vez requiere un cambio en la manera de ver el ejercicio de la práctica clínica, sin que tenga repercusiones en la retribución profesional por un trabajo de alta calidad.

La definición de la caries y su manejo, se han basado en paradigmas donde las bacterias de la biopelícula dental son protagonistas, generando varias teorías para explicar la patogénesis de la enfermedad.

Las teorías han evolucionado desde la "teoría parasitaria" que explicaba la aparición de la enfermedad por la presencia de microorganismos, pasando a la teoría químico-parasitaria y a la teoría proteolítica, que además de los microorganismos le dan importancia al efecto de la 
alimentación. Posteriormente, la teoría de la quelación que se centraba en que la causa de la caries es la proteólisis del tejido, y en las últimas décadas aparecieron dos teorías buscando explicar la enfermedad para poder prevenirla, estas son la teoría de la placa específica y la teoría de la placa ecológica (9).

Siguen estando vigentes conceptos apoyados en los estudios de Miller (10), cuando aisló bacterias de cavidad oral y encontró que eran capaces de producir ácido a partir de carbohidratos fermentables al ser incubadas a temperatura corporal, y que este ácido era suficiente para descalcificar los dientes, por lo que se puede decir que desde ahí se reconoce que la dieta y el medio oral hacen parte la patogénesis de la enfermedad, aunque la mirada reduccionista de la profesión al parecer centró sus acciones en las técnicas para remover la placa bacteriana como se conocía en ese momento, y en clasificar la dieta como cariogénica o no cariogénica, donde tanto las técnicas como la valoración del tipo de dieta se aplicaban de la misma manera a todos los individuos. Sin embargo, la prevalencia de la caries dental se mantuvo alta tanto en países desarrollados como en los países en desarrollo (11).

Más recientemente, cuando se aceptaba la hipótesis de la "placa específica" los tratamientos eran dirigidos a eliminar y prevenir la infección retirando tejido incluso sano para reemplazarlo con un material restaurador (12-14). En consecuencia, los enfoques para manejar y prevenir la caries condujeron la investigación hacia las vacunas, o al uso de antibióticos entre otros métodos para eliminar todos los microorganismos cariogénicos, especialmente a Streptococcus mutans, por ser uno de los primeros colonizadores de la superficie dental y por su capacidad de coagregación (11). 
En la actualidad se acepta la hipótesis de la "placa ecológica", que reconoce la participación del ambiente y del comportamiento de los individuos, en el transcurso de la enfermedad (9), lo que deriva en un manejo dirigido al control de los factores de riesgo, que por su puesto incluyen los efectos de las bacterias en la biopelícula, donde la mirada preventiva y el manejo conservador del tejido prevalecen, basados en que la caries ya no se ve como una enfermedad infecciosa, y el objetivo es controlar su actividad y no remover la lesión en si misma (15). Por eso aparecen estrategias de remoción de tejido carioso que involucran 4 esquemas: no selectiva, selectiva de tejido duro, selectiva de tejido blando y en dos pasos. Por medio de estas estrategias se intenta tener un manejo no invasivo de las caries dentales donde no hay necesidad de remover todas las bacterias, ya que al sellar con una restauración la cavidad, las bacterias que quedan en ésta se inactivan como consecuencia de la ausencia de nutrientes y muchas bacterias son incapaces de sobrevivir, por esto el selle de la restauración es fundamental. De esta forma, se preserva tanto tejido sano como tejido remineralizable, ayudando a mantener la vitalidad pulpar y así conservar la capacidad de reparación de la dentina (15-18).

Con base en esta teoría, la causa primaria de la enfermedad es el imbalance ecológico en composición y actividad de la biopelícula, generado por la ingesta abundante de carbohidratos fermentables y la pérdida de minerales del diente, que no alcanza a ser compensada por los procesos de desmineralización y remineralización de la saliva (19).

En esta teoría son evidentes varios cambios, el primero se refiere al papel de las bacterias endógenas que se conciben dentro de un ambiente (20,21), el segundo es el efecto metabólico de esa interacción, que se convierte en la causa de la enfermedad, y el tercero es el que señala que el 
comportamiento de los individuos es definitivo por su efecto tanto en la presencia de las bacterias como en el control del ambiente.

Desde ese momento el reto para prevenir la caries incluye el manejo del individuo como parte de sistemas más complejos que incluyen a sus familias, sus entornos laborales y en últimas hacen parte de los Sistemas de Salud.

Para el momento en el que se acepta la teoría de la placa ecológica ya Lederberg (2003) (22) había descrito un microbioma como la comunidad ecológica de comensales, simbióticos, y microorganismos patógenos que comparten un espacio corporal. Se considera que el microbioma que coloniza naturalmente los dientes en la salud es una comunidad de biopelículas que pueden contrarrestar la producción de ácido, a partir de la ingesta de hidratos de carbono de la dieta, para mantener una superficie dental intacta, por la producción de amoniaco a partir de arginina o urea (23). La disbiosis del microbioma se produce por un cambio en la composición bacteriana, asociado a la ingesta excesiva y frecuente de hidratos de carbono cuando la producción de ácido, supera la capacidad de amortiguación del microbioma saludable (24).

Las bacterias más importantes en la caries dental son: Streptococcus sobrinus, varias especies de Lactobacillus y en especial el $S$. mutans por su capacidad para convertir los azúcares en ácidos (acidógeno); crecer a pH bajo (acidófilo) y seguir produciendo ácidos a pH bajo (acidúrico) además de producir descensos rápidos en el pH del medio (25). 
Takahashi y Nyvad (2011) (26) incorporan la hipótesis de placa ecológica extendida, donde incluyen a otras bacterias tolerantes a los ácidos en la iniciación y progresión de la caries dental, resaltan la presencia de Actinomyces, Bifidobacterium, y otras especies de Lactobacillus. En la biopelícula dental las bacterias que regulan el efecto de las bacterias acidogénicas/acidúricas son: Streptococcus sanguinis y Streptococcus gordonii que hidrolizan la urea que llega a la cavidad oral a través de la secreción de las glándulas salivales y del fluido crevicular, produciendo amonio y $\mathrm{CO}_{2}$, se sabe que en individuos sanos la concentración oscila entre 1 y $10 \mathrm{mM}(27,28)$.

En la caries, igual que en otras patologías no transmisibles que afectan a las personas durante toda la vida, la participación de los factores de riesgo comportamentales que tienen efectos negativos en la salud bucodental está asociada a una dieta rica en azúcares libres y a una higiene oral insuficiente o inapropiada en cada individuo, y en el caso particular de la caries además al poco flúor disponible en el ambiente (29).

Las definiciones más recientes de caries, sin lugar a dudas muestran interacciones complejas, una de estas definiciones la considera una enfermedad multifactorial, compleja y reemergente causada por el desequilibrio fisiológico entre el mineral de los tejidos duros del diente y la biopelícula, inducida por bacterias endógenas y relacionada con los procesos de los individuos y las colectividades (30-32). La Asociación Dental Americana (33), la definió como enfermedad multifactorial, caracterizada por la destrucción de los tejidos del diente como consecuencia de la desmineralización provocada por los ácidos que genera la placa bacteriana a partir de los restos de alimentos de la dieta, esta última definición tiene un alcance más limitado al no darle importancia al papel de cada individuo en la enfermedad. Vale la pena resaltar que, ante la variedad de 
definiciones de la caries dental utilizadas por organismos altamente reconocidos en el mundo, es importante que el recurso humano en salud oral ajuste y/o cambie la definición de caries que utiliza, para orientar las decisiones clínicas en cada paciente, apoyando e impulsando mejoras en los esquemas de atención y remuneración de los sistemas prestadores de servicios, desde un trabajo interdisciplinario donde la práctica odontológica se reposicione.

Estas definiciones se apoyan en modelos de la patogénesis de la caries como el propuesto por Zero (34), que se basa en la hipótesis de la "placa ecológica" donde se analiza la patogénesis desde el periodo prepatogénico que reconoce lo que se requiere para estar sano, identifica y visibiliza los cambios iniciales de la fase subclínica no detectables con facilidad, dando inicio al periodo patogénico que termina en las secuelas asociadas a la pérdida de tejidos duros, este abordaje supera el concepto donde la caries era la cavidad $(35,36)$. La consecuencia lógica de los modelos de patogénesis de la caries dental aceptados hoy en día generó la aparición de modelos de detección de la caries dental, como el Sistema Internacional para la Detección y Evaluación de Caries ICDAS $^{\mathrm{TM}}$ por sus siglas en inglés (The International Caries Detection and Assessment System ${ }^{\mathrm{TM}}$ ), que hoy en día se conciben como una parte de los sistemas internacionales de clasificación y manejo de caries (ICCMS- International Caries Classification and Management System) que en el 2019 se ajusta en la guía de práctica clínica: CariesCare Practice Guide: Consensus on Evidence into Practice (30).

Los modelos de patogénesis incluyen información que ya había señalado Kleinberg (1961) (37) quien demostró una clara relación de causa y efecto entre la disponibilidad del substrato (glucosa) y la magnitud y duración de la caída del pH. Conocimiento que fue ampliado cuando Kleinberg y 
Jenkins (1964) (38), observaron la respuesta de $\mathrm{pH}$ en la placa de diferentes individuos, tomada de las mismas superficies después de comer. Ellos encontraron un $\mathrm{pH}$ alto en la mañana antes de desayunar, que luego bajaba cuando había carbohidratos fermentables disponibles en la boca, para convertirse lentamente en un $\mathrm{pH}$ básico después de un periodo de 3 horas y media.

El modelo de Zero (34), contempla otros factores locales que pueden minimizar o proteger a los individuos de sufrir la enfermedad, estos incluyen: al sistema inmunológico del huésped, la capacidad de la saliva para llegar a ciertas zonas y remineralizar y por supuesto a la higiene oral que en conjunto disminuyen la cantidad de microorganismos.

Entendiendo la patogénesis de la caries desde este modelo, el manejo de la enfermedad empezaría con dos medidas locales simultáneas, la primera tiene como propósito controlar la producción de ácidos de una placa ecológica, y la segunda, tiene como objetivo remineralizar de manera efectiva el tejido dental. Ambas medidas requieren el trabajo colaborativo y continuo entre el profesional y el paciente para generar y acompañar cambios en el comportamiento.

Para controlar la producción de ácidos se debe mejorar el esquema de higiene oral para desorganizar o eliminar la biopelícula de la superficie de los dientes, incluyendo: los momentos del día en los que se realiza la higiene oral, el análisis individualizado del cepillado, si se requiere algún tipo de asistencia o supervisión, la frecuencia con la que se realiza, y los implementos utilizados ajustados a la anatomía del individuo y a sus necesidades especiales, además del uso de seda dental y ayudas complementarias para eliminar la biopelícula de las superficies interproximales (39). La segunda medida local para remineralizar los tejidos desmineralizados y 
proteger los sanos, es el uso de los fluoruros, ajustados al riesgo individual, y a la actividad de las lesiones, que definen el tipo y concentración de fluoruro que se puede requerir, barniz de flúor si su uso es como tratamiento oportuno para inactivar lesiones (prevención secundaria), o fluoruro en barniz o gel para prevención primaria, sumados a las fuentes de flúor como crema dental y enjuagues por su aporte constante de fluoruro en la cavidad oral $(40,41)$.

Finalmente, el modelo incluye a varios factores que modifican indirectamente el proceso de la caries, como la edad, los factores genéticos, socioeconómicos, comportamiento del individuo y el manejo odontológico. Por esto es necesario un enfoque multivariado, en constante desarrollo, especificación y continua validación, con el fin de lograr prevención y tratamiento adecuado en cada paciente (28).

A pesar de aceptarse cambios en la definición de caries dental, producto de la incorporación de la evidencia, la aceptación de muchos odontólogos, habiendo transcurrido más de una década de la difusión del concepto actualizado de caries dental en el 2004, cuando se publicaron los resultados de la discusión sobre la definición moderna de caries dental, los cambios en el manejo de la patología aún no se han adoptado y prevalece un manejo restaurativo conocido como "fresar y sellar" sobre un manejo conservador basado en el manejo individualizado y preventivo (41). Un diagrama en la Figura 1, incluye los elementos que incluye la definición de caries y sus relaciones, como punto de partida para analizar las acciones que podrían contemplarse (figura 1). 
DIAGRAMA DE LOS COMPONENTES DE LA DEFINICIÓN DE LA CARIES DENTAL Y SUS RELACIONES

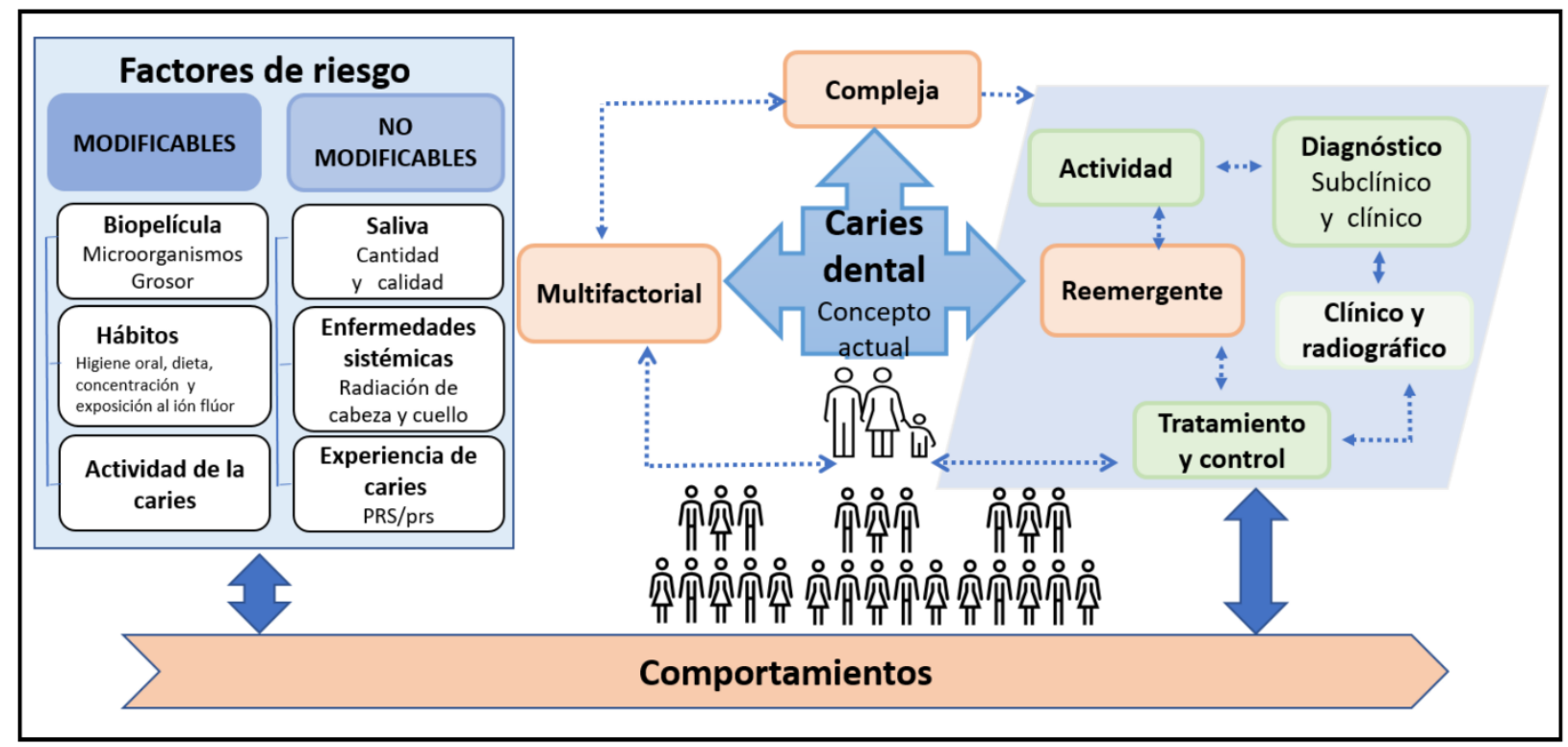

Fuente esquema de los autores. En el diagrama: PRS/prs: índice de infección radicular que involucra la pulpa en dientes permanentes y temporales. Las líneas interrumpidas señalan relaciones dinámicas entre componentes principales del diagrama.

\section{Acciones para abarcar la definición actual de caries dental}

Para abarcar el modelo de patogénesis y la definición actual de caries dental es importante identificar acciones que permitan prevenir, atender y controlar la patología. La caries es una enfermedad multifactorial, varios factores además de las bacterias y el grosor de la biopelícula influyen en la magnitud de las fluctuaciones del pH, el más importante es la dieta, principalmente el consumo de azúcares fermentables, otros factores son la concentración de ion fluoruro al que está expuesto el individuo y la tasa de secreción salival (43), a los que se suman: el ingreso económico, la educación, la vivienda, la nutrición, los hábitos y las enfermedades sistémicas, entre otros (44). En consecuencia, una enfermedad multifactorial requiere explorar muchos más aspectos que la detección de biopelícula o preguntar por la dieta, para poder trabajar de manera colaborativa con el paciente para encontrar cambios contextualmente viables que incluyan la educación, ingreso económico, nutrición y acceso a servicios de salud del grupo familiar entre otros. Para controlar y 
prevenir la enfermedad, se requiere el desarrollo de habilidades de comunicación, fundamentales en la indagación que superan el diligenciamiento de información en un instrumento como la historia clínica (45). Al reconocer cuales son los múltiples factores que explican el proceso de salud y enfermedad de cada paciente la perspectiva de atención cambia, de tener como centro los tratamientos clínicos ofrecidos directamente por el profesional, a una perspectiva de atención centrada en el paciente-enfermedad.

$\mathrm{Al}$ tener en cuenta la dieta del paciente para tomar decisiones de manejo se debe tener presente que la dieta se ha relacionado siempre con la caries dental, porque los cambios en la alimentación a través de la evolución del hombre han mostrado alteraciones en los dientes compatibles con caries dental. Dentro de estos cambios, el primero parece haber ocurrido cuando el hombre empieza a consumir frutas y otros vegetales como parte de su dieta, incluyendo modificaciones importantes en los tipos de alimentos que se consumían hasta el reporte de la primera "epidemia de caries" ocurrida en 1950 (46) y el último cuando se masificó el consumo de azúcares refinados en los países industrializados y la caries aumentó de manera significativa.

Al determinar acciones para controlar el riesgo de caries asociado a la dieta, se debe considerar que la frecuencia del consumo y la consistencia del azúcar son más importantes que la cantidad de la ingesta (47). La frecuencia determina la duración del azúcar disponible para los microorganismos y la consistencia, determina la velocidad con que puede ser eliminada de cavidad oral, las soluciones de azúcar son menos cariogénicas al ser comparadas con su presentación sólida (48). Al hablar de frecuencia, se sabe que cuando baja el $\mathrm{pH}$, la saliva necesita tiempo para lograr neutralizar estos ácidos, el tiempo necesario varia de persona en persona, pero en general, un 
paciente con una biopelícula gruesa por una poca o mala higiene oral, necesita en promedio 2 horas para que su saliva logre un efecto buffer y neutralice el pH. Si se ingiere azúcar de nuevo, antes de este tiempo de recuperación, la continua producción de ácido generará un proceso de desmineralización en la superficie dental (49). Esto muestra claramente que los múltiples factores de riesgo se asocian entre ellos en cada individuo y dependen de sus hábitos y comportamientos. Lograr cambios en los comportamientos asociados a la dieta representa un reto para el profesional de la salud porque estos comportamientos a su vez, están asociados a los ciclos de vida, a las inequidades y a su entorno, por lo que el trabajo en cambios de comportamiento debe racionalizarse de acuerdo con lo que puede o no hacer el paciente por su salud y el tiempo que requiere ajustar su comportamiento, nuevamente conseguir esta meta necesita cambiar la perspectiva de cuidado de centrado en el tratamiento, pasando por el centrado en el paciente-enfermedad hasta llegar a una perspectiva de cuidado centrada en la persona $(3,50)$

Algunos alimentos que tienen un rol cariogénico son:

Azúcares convencionales: los monosacáridos (glucosa y fructuosa) y disacáridos (sacarosa, lactosa, maltosa) son los carbohidratos fermentables más comunes y cariogénicos. Aunque no hay mucha diferencia entre la cariogenicidad de la sacarosa y la fructuosa, la sacarosa es considerada la más cariogénica de todas, probablemente por ser la que se consume con mayor frecuencia. Algunos de los azúcares convencionales que se le agregan a las bebidas y comidas por parte de las fábricas se consideran azúcares libres, estos son diferentes a los azúcares presentados de manera natural como miel, jarabe, jugo de futas, concentrados de jugos de frutas (51). La relación directa entre consumo de azúcares y experiencia de caries está confirmada a tal punto que la OMS, realizó un cambio en la recomendación de consumo de azúcares libres, pasando del 10 al 5 \% (2003) para 
reducir la obesidad, diabetes tipo 2, y caries dental $(51,52)$. Aunque el $S$ mutans, en ausencia de azúcar puede colonizar la superficie dental, en presencia de ésta incrementa su habilidad para hacerlo (53).

Almidón: es importante en la dieta del ser humano e incluye un gran porcentaje de carbohidratos, alrededor del $50 \%$ de los carbohidratos consumidos vienen del almidón (54). Aunque son carbohidratos complejos y deberían ser más difíciles de fermentar al tener un tamaño molecular muy grande, tienen un potencial cariogénico en pacientes con alto riesgo a caries y lesiones activas, ya que en este caso puede ser hidrolizado por la saliva y la amilasa de la placa y convertirse en maltosa, glucosa y dextrinas (49). Se ha demostrado que una combinación de almidón altamente procesado con azúcar genera un biofilm más grueso, más acidogénico y deletéreo que los vistos en sacarosa y glucosa solas. Esto se le atribuye a la enzima alfa amilasa presente en saliva (55). Polímeros de glucosa (oligosacáridos): se encuentran en alimentos procesados (en bebidas, productos lácteos, bebidas energizantes y endulzantes) y son conocidos como almidón hidrolizado. El almidón hidrolizado afecta más a la dentina que al esmalte cuando baja el pH (56). Estos polímeros de glucosa, no solo se encuentran en bebidas deportivas, barras y suplementos energéticos, y en suplementos para personas mayores. Esto es de gran importancia, en pacientes con exposición de dentina o donde hay exposición radicular, ya que aumenta el riesgo de caries dentinal y radicular (54).

Algunos alimentos que tienen un potencial anticariogénico son:

Polioles: son carbohidratos de lenta digestión (azúcares de alcohol), se encuentran en frutas, vegetales y hongos. Al no tener alto valor nutricional no se absorben por completo, sirven para 
disminuir la ingesta calórica y se han considerado anticariogénicos. Se emplean en gomas de mascar principalmente. Su eficiencia se atribuye a la estimulación del flujo salivar por la masticación, aumentando el pH y generando remineralización de lesiones cariosas en estadios tempranos. El poliol más estudiado de todos es el Xilitol, que ha demostrado ser un agente en la prevención de caries $(54,57)$.

Comidas funcionales y compuestos fenólicos: se ha propuesto que comidas funcionales, nutraceúticos, y probióticos de origen natural puede proteger a los individuos de desarrollar caries dental, y que antioxidantes en el polifenol en frutas, vegetales y granos, son potencialmente activos en contra de la caries (flavonoides y carotenos, ácidos fenólicos), al reducir el crecimiento bacteriano (58).

Ácidos grasos: tienen una actividad antimicrobiana y propiedades bacteriostáticas al no poder ser metabolizados por las bacterias del biofilm, pero cambiar la ingesta de carbohidratos por grasas, puede aumentar el riesgo a enfermedades crónicas, por lo cual, si se cambia la dieta, debe realizarse de manera adecuada $(49,59)$.

Proteínas: son las encargadas de proveer la urea en la saliva, que es hidrolizada por la ureasa y produce amonio. El amonio tiene un $\mathrm{pH}$ alcalino y causa un aumento en el $\mathrm{pH}$ (23).

La leche y productos lácteos: contienen una variedad de agentes como proteínas buffer, iones de calcio y de fosfato, proteínas no fosforiladas y fosfopéptidos. Se ha demostrado que las fosfoproteínas pueden ayudar a mineralizar la hidroxiapatita y que los fosfopéptidos de caseína, presente en los lácteos, reducen el rango de disolución de hidroxiapatita. La lactosa es poco 
cariogénica, pero cuando se combina con sacarosa o se consume de manera frecuente como al amamantar es altamente cariogénica $(60,61)$.

La caries está asociada a la frecuencia de exposición y patrones de consumo de diferentes alimentos. Se ha reportado que niños que comen "snacks" a la hora de la comida tienen mayor índice de caries. Entre estos snacks se asociaban pan, galletas, mermelada, bananas, yogurt con azúcar y entre los alimentos que son considerados protectores y que reflejan la aparición de menos lesiones nuevas son el queso, las nueces, pescado, granos, vegetales (62).

La caries se considera compleja, porque el resultado de las múltiples interacciones entre la biopelícula y los demás factores relacionados con la enfermedad tienen desenlaces muy variados, es decir la presencia de biopelícula solamente, no explica la extensión, actividad y severidad de la patología. Un ejemplo de ello lo muestra la investigación de Bowen en 1977 (63) en dos pueblos colombianos, relativamente aislados, Heliconia donde hay baja prevalencia de caries y San Matías con una prevalencia de caries considerablemente mayor. En los dos lugares, los niños consumen grandes cantidades de azúcar (panela principalmente), no hay flúor en las fuentes de agua de consumo habitual (menos de 0,2 ppm) y en general la dieta es pobre en proteínas. Los resultados mostraron que mientras los niños de 8 a 14 años de San Matías tenían índices COPs de 19, y solo el $2 \%$ no tenían caries, los niños de Heliconia tenían COPs de 6,7 y aproximadamente el $17 \%$ no tuvieron caries, aunque todos los niños tenían biopelícula (63).

Frente a la complejidad de la caries es claro que los protocolos de manejo deben ser individualizados y basados en trabajo colaborativo donde tanto el paciente como el profesional 
deben cumplir acciones particulares tanto en el autocuidado como en el consultorio para lograr controlar la enfermedad. Si bien es cierto que las enfermedades pueden ser definidas universalmente, los procesos de salud-enfermedad son diferentes en cada individuo.

La caries se considera una enfermedad reemergente, porque puede ser erradicada de un individuo, pero si se vuelve a presentar el imbalance entre la biopelícula dental y la concentración de minerales en los tejidos duros del diente, las lesiones cariosas pueden volver a aparecer. Se sabe que, con la eliminación regular de la biopelícula y el uso de fluoruros en cremas y enjuagues bucales como elementos del cuidado en casa, o administrados por el odontólogo, se retrasa o detiene la progresión de la caries dental, pero los datos de prevalencia e incidencia de la enfermedad han demostrado que estas medidas son insuficientes.

En el momento en el que la patología se haya controlado y se pueda considerar al individuo sin caries dental, el concepto de la reemergencia es muy relevante, de ahí la importancia del esquema de controles individualizados, que deben facilitar al paciente y al profesional, valorar el impacto de las acciones realizadas durante la atención clínica y el trabajo en casa para lograr y mantener la salud. Para alcanzar esta meta es necesario repensar la relación odontólogo paciente, y pasar del odontólogo que ofrece tratamiento y el paciente que lo recibe pasivamente, a modelos de trabajo colaborativo, como el que ofrece la entrevista motivacional donde el odontólogo es un facilitador y el paciente se reconoce como un sujeto activo en su proceso de salud- enfermedad, para lograr los cambios de comportamiento que le permitirán mantener la salud al lograr controlar los factores de riesgo $(64,65)$. No parece insensato pensar que el comportamiento que un individuo ha tenido 
durante un período largo en su vida va a cambiar, si no se trabaja en el cambio por el tiempo suficiente para que se vuelva un hábito saludable dentro de un estilo de vida saludable (66).

Otro factor que debe tenerse en cuenta para evitar la reemergencia es que los ciclos de vida de un individuo afectan sus comportamientos, como ejemplos se tiene que el ingreso al colegio, a la universidad, al trabajo, o los cambios asociados a cualquier condición sistémica entre otros, tienen consecuencias en la historia natural de la patología, por eso, tanto pacientes como profesionales deben estar atentos al efecto que esos cambios puedan tener en la caries dental y en la salud oral en general, buscando el desenlace deseable que se refiere a lograr que los dientes sanos se mantengan sanos en el tiempo (65).

Realizar controles en el manejo moderno de caries se considera una decisión para preservar tejido, evitando la reemergencia, sobre todo si se sabe que el efecto de los cambios en el pH se refleja en los tejidos dentales, clínica o subclínicamente (ultraestructuralmente). El efecto bioquímico incluye una pérdida de minerales que conduce a la disolución de los tejidos duros dentales, que ya en la fase subclínica de la enfermedad, puede ser detectada por una ligera mancha blanca en la superficie del esmalte en presencia o ausencia de humedad; con mayor disolución de los tejidos, ya en la fase clínica las lesiones se ven, sin pérdida de tejido pero con cambios de color; luego las lesiones moderadas pueden presentarse desde microcavidades detectables a cambios de color bajo superficies continuas de esmalte, imperceptibles para el paciente al ser principalmente asintomáticas; mientras que las lesiones severas presentan desde una discontinuidad en el esmalte con afectación de dentina, hasta la destrucción total de los dientes. El tejido dental así se encuentre 
rehabilitado, es susceptible a la reemergencia de la caries, asociada tanto a la estructura dental como al material restaurador $(67,68)$.

Adicionalmente las lesiones de caries en el esmalte pueden estar activas o inactivas, independientemente de la severidad (magnitud del daño o pérdida de tejido). Las activas incluyen erosión de la superficie y porosidad subsuperficial y en un diente vital hacen que la dentina reaccione al estímulo con la biopelícula produciendo esclerosis tubular y dentina secundaria o terciaria; y en las inactivas o detenidas aunque no presentan aspecto erosionado, la pérdida mineral subsuperficial permanece (43), como las bacterias en el biofilm están metabólicamente activas, si la biopelícula dental no es removida frecuentemente una lesión cariosa inactiva puede activarse, y a su vez si se suman la remoción efectiva de la biopelícula con el efecto remineralizador de la saliva y del flúor aplicado de diferentes maneras, una lesión activa puede inactivarse. Esta dinámica sucede en cualquier etapa de la progresión de la lesión, y está asociada con la biopelícula (67).

La caries está relacionada con Procesos sociales de los individuos y las colectividades (69, 70), las últimas investigaciones en salud pública han mostrado que la edad, (principalmente niños pequeños) y el gradiente de inequidades sociales cambian los patrones de aparición de la enfermedad, un nivel socioeconómico bajo, se asocia de manera significativa con lesiones cariosas o experiencias de caries (71).

En países desarrollados y subdesarrollados existe una escala de inequidades bien establecida donde la problemática en salud oral impacta la salud pública en países con altos ingresos por un acceso 
restringido a salud oral. En el mundo se observa mayor prevalencia de enfermedades orales en poblaciones pobres o vulnerables, donde no hay programas educativos o de prevención existiendo una marcada diferencia entre clases sociales, nuevamente por acceso a salud oral. La caries continúa siendo la enfermedad crónica más común en niños, generando una carga financiera grande a la sociedad, por lo que es más rentable para los gobiernos hacer educación y prevención desde la edad prenatal (72-74).

Tanner 2018 (25) comparó la microbiota de caries dental en individuos con caries activa y libres de caries de Rumania y Suiza encontrando un microbiota más acidogénica en los niños rumanos con caries, principalmente $S$. mutans y $S$. sobrinus y otros Streptococcus no mutans, mientras que en los niños de Suiza con caries estaba presente Actinomyces taxa y Streptococcus constellatus.

En niños de 5 años se observó mayor número de lesiones cariosas cuando la madre tenía un bajo nivel educativo, gran número de familiares viviendo con el niño, permiso de consumo de snack y cepillado dental no asistido por adultos. Se ha demostrado que la incidencia de caries en los primeros molares podría reducirse si hay un cepillado asistido y supervisado por los primeros 2 años y medio cepillándose 2 veces al día $(49,75)$.

Las inequidades sociales y el curso de vida de los individuos han sido asociados con la presencia de caries, en consecuencia, la capacidad, las oportunidades y lo que motiva a los individuos es diferente, y debe ser considerado para generar cambios en su comportamiento (76). 
La integración de política pública para la promoción primaria en la salud y prevención de las enfermedades orales pueden ser las intervenciones públicas más efectivas y menos costosas. Trabajar en promoción y prevención en consultorios particulares sin duda también aportará (77).

\section{Acciones ajustadas al modelo ICCMS para llevarlo a la práctica}

El modelo para el manejo de caries dental más reconocido es ICCMS ajustado en la guía práctica "CariesCare", este sirve para orientar decisiones, no son protocolos, por eso no son aplicables hasta que los individuos lo entiendan y lo aprendan a usar en su propia práctica.

La primera reflexión para llevar a la práctica estos modelos, se basa en que el cuidado de la salud puede ser abordado desde diferentes posturas, la más común encontrada en odontología es la centrada en el tratamiento que el profesional-estudiante pueden ofrecer, y su principal limitación es que no les resulta fácil individualizar el manejo integral de un paciente, por eso varias investigaciones proponen estrategias para migrar hacia el cuidado centrado en la enfermedad del paciente, facilitando la individualización, aunque la meta final es la de alcanzar el cuidado centrado en la persona que supera al anterior, porque vincula el análisis del contexto, lo que permite encontrar cambios del comportamiento que resulten viables para el paciente (66).

Los modelos requieren como primer paso recoger la información necesaria para poder entender o explicar la enfermedad del paciente, para hacerlo, es necesario superar los instrumentos donde se registra información, como la historia clínica y las encuestas CAPS, entre otros, porque promueven un abordaje reduccionista del profesional, que no favorece la indagación y dificulta enormemente individualizar la historia natural de la enfermedad en cada paciente. 
Aristizábal y colaboradores (78) mostraron que es común encontrar que los estudiantes de odontología hacen preguntas al paciente siguiendo un formato, sin detenerse a analizar si esa información corresponde a la realidad del paciente y sin ningún tipo de profundización, el ejemplo más claro estuvo en preguntas como ¿cuántas veces al día se cepilla los dientes? donde las respuestas fueron sistemáticas indicando que 3 veces al día, cuando se cambió la manera de preguntar, por una pregunta abierta individualizada, seguida de preguntas para acompañar y profundizar la información, dónde no se juzga si la respuesta es la que la teoría pide, o los medios de comunicación transmiten, se obtuvo un panorama ajustado a la realidad del paciente. La secuencia que tuvo más acogida y se iba ajustando: ¿Cuénteme, como fue su cepillado ayer? ...se levantó y? ... comió a las 10 am y qué hizo? hasta finalizar la jornada. La información obtenida para muchos pacientes fue, que en su mayoría no se cepillan 3 veces al día, los momentos de cepillado no son funcionales teniendo en cuenta los que se sabe de los cambios de $\mathrm{pH}$ demostrados por Kleinberg (37), es decir se en la mañana se cepillan solamente antes del desayuno, no hay cepillado después del almuerzo, por falta de tiempo, no llevan el cepillo, o no encuentran un lugar donde hacerlo en privado, y varios se cepillan después de la comida, pero vuelven a comer antes de acostarse a dormir. Con más información es posible individualizar los ajustes necesarios para mejorar su salud oral.

Una buena indagación es la que va a permitir valorar el riesgo individual de caries de cada paciente, al poner en la balanza por un lado los factores protectores y por otro lado los factores de riesgo, considerando las particularidades de niños y ancianos, se incluyen factores de riesgo sociales, médicos, de comportamiento y factores de riesgo clínicos. Los sistemas han seleccionado factores 
que presentan evidencia de ser los de mayor riesgo para desarrollo de caries dental. Los factores que determinan un alto riesgo de caries incluyen hiposalivación, experiencia de caries reciente y presencia de caries activas, $\mathrm{PRS} / \mathrm{prs}(\mathrm{P} / \mathrm{p}$ procesos de caries que involucran pulpa dental, $\mathrm{R} / \mathrm{r}$ procesos de caries que destruyen estructura dental - no restaurable, S/s supuración por fistula o canal radicular (68).

El primer paso permite individualizar a un paciente incluyendo la valoración del riesgo, que puede ser alto o bajo, para poder iniciar el recorrido del segundo paso, el diagnóstico clínico. La detección y evaluación de las caries dirige la toma de decisiones de manejo, por lo que usa sistemas como el ICDAS donde se emplea una combinación de la información clínica y radiográfica junto con la actividad de la lesión, para poder pensar en preservar el tejido dental que no requiera ser retirado, incluyendo acciones para inactivar lesiones rápidamente con barniz de flúor. Un aspecto fundamental es la importancia que tiene diagnosticar los dientes sanos pensando en que estos requieren acciones para mantenerlos sanos, por eso clínicamente abarca desde un diente sano ICDAS 0, hasta la pérdida de gran cantidad de tejido dental ICDAS 6 y radiográficamente de R0 que corresponde a sano hasta RC6 estadio extenso. El diagnostico combinado del estadio de la caries, dictamina si está sano, si hay lesiones iniciales, moderadas o extensas, y adicionalmente se especifica si la lesión está aparentemente activa o no. Adicional a esto, los diagnósticos se deben asociar con el tipo de restauración o sellante presente, CARS. De igual manera existe sistema para el diagnóstico de caries radicular, basándose en la pérdida del contorno anatómico y profundidad de la lesión (68). 
El modelo propone, integrar la información obtenida, el estadio de la severidad y la probabilidad de actividad de cada lesión con la clasificación de riesgo del paciente para poder tomar las decisiones adecuadas para cada individuo (78). El consenso de caries recomienda realizar mínimo un entrenamiento en línea, no emplear instrumentos cortantes durante la detección de las lesiones para evitar más daño al tejido y recuerda las limitaciones de las interpretaciones radiográficas. "CariesCare" propone diagramas de flujo para la toma correcta de decisiones para el diagnóstico y para la clasificación del riesgo, para poder escoger el tratamiento adecuado, con las siguientes características: que sea individualizado para prevención, control y preservación de tejido incluyendo acciones de cuidado en casa e intervenciones en consultorio, junto con la programación de intervalos de controles basados en el riego (30).

El paso siguiente consiste en planear y ejecutar el plan de tratamiento individualizado, en este momento los pacientes deben ser sujetos activos que participen en la planeación, y se encuentren dispuestos y comprometidos con el plan de tratamiento. Este tratamiento debe involucrar el manejo especifico de riesgo de caries del paciente, manejo individual de lesiones cariosas dependiendo de su extensión y actividad, y debe ser diferencial entre dientes temporales y permanentes.

Para el manejo específico del riesgo del paciente las acciones deben estar centradas en el paciente y sus necesidades, donde el tiempo del consultorio debe incluir un trabajo colaborativo no instructivo, para facilitarle al paciente el control de los factores de riesgo que en él se pretendan controlar. Un ejemplo de trabajo colaborativo que permite alcanzar esta meta es la entrevista motivacional. Está apareciendo evidencia, que muestra que para poder implementar este abordaje parecen ser más adecuados las secuencias de entrevista motivacional a lo largo del tratamiento, y 
con refuerzos específicos en los controles, porque una sola sesión utilizando la entrevista motivacional, no es suficiente para la mayoría de los pacientes y el acompañamiento depende de la posición del paciente frente al cambio, hay pacientes que nunca han considerado cambiar a pesar de haber recibido información a lo largo de la vida; otros, han considerado cambiar después de interacciones con profesionales de la salud, o por experiencias de personas cercanas, pero no han iniciado el cambio; otros, se preparan para el cambio, por ejemplo comprando los elementos de higiene oral que le recomendó el profesional, pero no mantienen el cambio; mientras que otros, cambian el comportamiento no saludable, pero ante un estímulo o una situación negativa (falta de tiempo, exceso de trabajo..) retroceden, y pueden no seguir intentando cambiar, el ideal es que se acompañe al paciente a mantener el cambio por periodos más largos fortaleciendo su grado de entendimiento de su proceso de salud- enfermedad (64).

El manejo de las lesiones cariosas dependerá de su extensión y actividad, clínica y radiográfica. Se incluye un manejo no operatorio con prevención primaria para el control de factores de riesgo, la inactivación de lesiones iniciales con barniz de flúor y el uso de sellantes o sellantes más barniz de flúor siempre acompañado de controles. El manejo no operatorio abarca lesiones iniciales que se puedan limpiar, y en las lesiones interproximales, se puede realizar un abordaje como la infiltración con resinas o sellantes (17), es muy importante el diagnóstico clínico en estas zonas y hacer uso de alternativas para una valoración. El manejo operatorio busca siempre una preservación dental y se realiza en lesiones cavitadas. En lesiones cavitadas de muy difícil acceso donde no se puedan limpiar y el uso de un sellante no es indicado, es recomendado realizar un abordaje con operatoria. En dientes vitales, con lesiones profundas, es más importante mantener la vitalidad pulpar que el éxito de la restauración, mientras que, en lesiones no tan profundas, la 
longevidad de la restauración debe ser más importante. En retratamientos de restauraciones, se debe intentar reparar, pulir o brillar de nuevo siempre que sea posible, y como última opción reemplazar la restauración completa $(17,15)$. Es importante resaltar que un paciente que entre a fase de mantenimiento requiere tanto el control efectivo de los factores de riesgo como que el individuo esté libre de caries.

\section{DISCUSIÓN}

Para cerrar la brecha entre el conocimiento sobre la caries dental y la práctica clínica, Fontana y Zero en el 2007, muestran la importancia que tiene la formación del talento humano en odontología, al identificar barreras que dificultan la apropiación del entendimiento actual de la patología en las facultades de odontología que incluyen la estructura misma de las facultades, la calibración de profesores y estudiantes y el poder trabajar desde un marco que pueda responder a las expectativas de salud pública (79), esto hace pensar que superando esas barreras, desde la academia se pueda superar que la difusión del conocimiento en caries esté atomizada y se dificulte aún más que se adopte la comprensión actual de la caries dental.

Incluir en la estructura de la formación del talento humano en salud oral, el conocimiento que para el manejo de la caries dental se produce desde las ciencias del comportamiento, para integrarlo con el conocimiento publicado en los espacios reservados para los avances en las ciencias básicas y la investigación clínica probablemente favorecerá que el talento humano reconstruya el marco conceptual en el que se fundamentan sus decisiones clínicas, para llevarlas a su quehacer diario. 
La presente revisión integrativa busca proponer acciones clínicas concretas basadas en conceptos que nutren el entendimiento actual de la caries dental, partiendo de la evolución del papel de las bacterias en el concepto de esta patología.

Llama la atención que aunque las bacterias participan activamente en la patogénesis de la caries dental, y que su presencia no explica la aparición de la enfermedad, su severidad ni la extensión de las lesiones, aún es común que los clínicos consideren que controlar los factores de riesgo de la enfermedad, equivale a "controlar la biopelícula" durante la o las primeras sesiones de atención clínica, repitiendo esquemas similares en todos los pacientes, probablemente escogiendo técnicas de cepillado diferentes para adultos y niños. Pero sin analizar que los pacientes regresan con nuevas lesiones, o que aquella información que transmiten a los pacientes funciona en unos, pero no en otros. Entonces, ¿dónde queda el componente multifactorial de la enfermedad? ¿qué significa controlar la biopelícula? ¿Acaso, algo más que identificar según el índice utilizado la cantidad depositada sobre los dientes, o su calidad?

Otro tanto ocurre con el análisis de la dieta de los pacientes, acaso se considera que de esta depende la actividad de la biopelícula, ¿qué pasa con los otros factores de riesgo? ¿por qué hoy se acepta manejar a los pacientes según el riesgo para desarrollar caries dental? ¿por qué es necesario analizar si los factores protectores neutralizan a los factores de riesgo y la enfermedad se mantiene controlada?

La reflexión central para aquellos que superan la transmisión de información de las técnicas para remover la biopelícula en involucrar aspectos como el efecto de los alimentos en el $\mathrm{pH}$ de la biopelícula y por lo tanto en la regulación entre bacterias acidogénicas y acidúricas $(25,26)$ es ¿por 
qué sus acciones no funcionan en todos los pacientes, probablemente porque los seres humanos tienen comportamientos diferentes y lo que motiva a unos y a otros es personal.

Si la caries dental se considera multifactorial, compleja, reemergente y modificada por los individuos y las comunidades, la necesidad de entender e incorporar su manejo como un sistema que incluye acciones perfectamente engranadas y cíclicas a lo largo de la vida es algo necesario, y modifica ciertamente el manejo tradicional centrado en los tratamientos, quizás además fraccionado en procedimientos, que se enseña aún en algunos programas de odontología. Entender los elementos del sistema y su papel en el manejo de la caries y cómo funcionan como la maquinaria de un reloj como se diagramó inicialmente por la organización ICCMS, se requiere y supera una lista de chequeo de acciones cumplidas, sobre todo porque cada acción depende de la persona que se está atendiendo.

Considerando la importancia de entender que del comportamiento de las personas, profesionales y pacientes depende el control de enfermedades prevenibles como la caries dental vale la pena repensar los currículos en las facultades de odontología. Reconocer elementos como de qué dependen los comportamientos, cómo se pueden abordar para favorecer cambios en las conductas asociadas a los hábitos, la importancia del análisis del peso que tiene el contexto en las decisiones de las personas, de ahí que se requiera trabajar teniendo como centro de las decisiones a las personas, y para esto no sirve llenar los formatos de las historias clínicas, pensar en hacer tratamientos para reparar secuelas sin trabajar en el control temprano de la enfermedad de la mano de un trabajo exhaustivo y continuo de los factores de riesgo, para lo que es importante indagar 
por cada uno, ponderar su efecto en la patología de cada paciente, y cómo hacerlo sin las competencias de comunicación que requiere todo el talento humano en salud.

Indagar "pensando en el conocimiento científico", en un aspecto como la información sobre el momento del día en el que el paciente se cepilla, el cepillo dental que puede comprar, cómo trabajar en conjunto con él para que sea un paciente activo que decida por su salud y trabaje por ella, ayudará a sin duda a lograr que, desde cada individuo y su entorno familiar, como miembros de una comunidad quizás sea posible avanzar en el control de esta patología.

Finalmente, las decisiones del talento humano en salud oral y su capacidad de trabajo con otras disciplinas favorecerá el trabajo centrado en las personas y el resultado se reflejará en los indicadores de salud oral y un buen escenario es sin duda el que se da en las universidades.

\section{CONCLUSIONES}

Aceptar el entendimiento actual de la caries dental obliga a manejarla como un sistema, donde el centro de las decisiones es el individuo o la comunidad, y como proceso requiere que cada elemento se integre y modifique a los otros elementos para alcanzar los desenlaces esperados en salud, educación y políticas, basados en la evidencia disponible. Este abordaje implica que cada país debe proyectarse dentro de su realidad, sin adoptar modelos completos de otros países, sin análisis profundos que respondan a sus necesidades en salud. 
En la formación del talento humano en salud bucal, se requiere la inclusión de escenarios, en los que el profesional aborde al paciente con caries dental bajo una nueva propuesta en su práctica clínica. Para integrar el entendimiento actual de la enfermedad se requiere que sea menos instrumentalizada (historia clínica, tratamientos, requisitos, indicadores requeridos por las instituciones), centrada en la persona, con esquemas de trabajo colaborativo donde la corresponsabilidad entre el profesional y un paciente activo permitan lograr mejores indicadores en salud oral, que incluyan mantener dientes sanos y para que un paciente odontológico sea dado de alta debe tener controlados los factores de riesgo y la enfermedad.

Considerando que la caries es una enfermedad prevenible el manejo centrado en la persona favorecerá los cambios en el comportamiento que se requieren para controlar los factores de riesgo modificables y minimizar el impacto de aquellos no modificables. Dada la dinámica descrita entre la actividad-inactividad-actividad de las lesiones cariosas el control de los factores de riesgo se hace durante toda la vida y se ajusta al curso y ciclo de vida de cada individuo, este postulado administra las intervenciones en prevención primaria que deben incluirse en la práctica privada y dentro de los planes de salud que ofrecen las instituciones prestadoras de servicios de salud oral.

\section{RECOMENDACIONES}

Diseñar programas de salud oral centrados en las personas, en consecuencia, ajustados al contexto y a la política pública, basados en cambios viables para los individuos y las particularidades de las comunidades incorporando el entendimiento actual de la caries dental. 
Incluir en los programas de formación del talento humano en odontología las competencias necesarias para trabajar en los cambios de comportamiento que son la base de la prevención de la caries dental.

Fortalecer las habilidades comunicativas del talento humano en salud oral para realizar mejores procesos de indagación que permitan individualizar el manejo de los pacientes.

Consolidar el trabajo multidisciplinario con disciplinas como psicología, nutrición y medicina familiar para trabajar centrados en las personas.

\section{REFERENCIAS}

1. Bordoni N, Caries dental: una mirada actual para una vieja problemática. Universitas Odontologica 2013; 32(68) :81-97.

2. Lomas J, Culyer T, McCutcheon C, McAuley L, Law S. Conceptualizing and combining evidence for health system guidance. Ottawa: Canadian Health Services Research Foundation; 2005.

3. Asimakopoulou K, Newton JT. The contributions of behaviour change science towards dental public health practice: a new paradigm. Community Dent Oral Epidemiol. 2015 feb; 43(1): 28. https://doi.org/10.1111/cdoe.12131

4. GBD 2016 Disease and Injury Incidence and Prevalence Collaborators Global, regional, and national incidence, prevalence, and years lived with disability for 328diseases and injuries for 
195 countries, 1990-2016: a systematic analysis for the Global Burden of Disease Study 2016 Lancet. 2017; 390(10100): 1211-1259. https://doi.org/10.1016/S0140-6736(17)32154-2

5. Phantumvanit P, Makino Y, Ogawa H, Rugg-Gunn A, Moynihan P, Petersen PE, Evans W, Feldens CA, Lo E, Khoshnevisan MH, Baez R, Varenne B, Vichayanrat T, Songpaisan Y, Woodward M, Nakornchai S, Ungchusak C. WHO Global Consultation on Public Health Intervention against Early Childhood Caries Community Dent Oral Epidemiol. 2018 Jun; 46(3): 280-287. https://doi.org/10.1111/cdoe.12362

6. World Health Organization. World Oral Health Report 2003. Published 2003. Accessed 15 February, 2018

7. Naydú Acosta Ramírez, Rolando Enrique Peñaloza, Jesús Rodríguez García, Estudio Cendex Carga de enfermedad en Colombia 2005: Resultados alcanzados. Documento Técnico ASS/1502-08 Bogotá, octubre de 2008.

8. Whittemore R, Knafl K. The integrative review: updated methodology. J Adv Nur. 2005; 52(5): 546-553. https://doi.org/10.1111/j.1365-2648.2005.03621.x

9. Marsh PD. Microbial ecology of dental plaque and its significance in health and disease. Adv Dent Res. 1994; 8(2): 263-271. https://doi.org/10.1177/08959374940080022001

10. Köhler W. Miller WD. The Micro-Organisms of the Human Mouth (Unaltered Reprint of the Original Work Published in 1890 in Philadelphia) PA: SS White and Co. Reprinted, 1973. https://doi.org/10.1002/jobm.19740140117

11. Kleinberg A mixed-bacteria ecological approach to understanding the role of the oral bacteria in dental caries causation: an alternative to Streptococcus mutans and the specific-plaque hypothesis. Crit Rev Oral Biol Med 2002; 13(2): 108-125. https://doi.org/10.1177/154411130201300202 
12. Black GV. (1917) A work on operative dentistry: The technical procedures in filling teeth. Chicago, Estados Unidos. Médico-Dental Publishing.

13. Loesche WJ. Role of Streptococcus mutans in human dental decay. Microbiol Rev 1986; 50(4): $353-380$

14. Taubman MA, Smith DJ. Vaccination: a cariostatic option? In: Cariology for the nineties. Bowen WH, Tabak LA, Editors University of Rochester Press, New York, USA. 1993; 441445

15. Schwendicke F. Removing Carious Tissue: Why and How? Monogr Oral Sci. 2018; 27: 5667. https://doi.org/10.1159/0004878322

16. Schwendicke F. Contemporary concepts in carious tissue removal: A review. J Esthet Restor Dent. 2017; 12;29(6): 403-408. https://doi.org/10.1111/jerd.12338

17. Schwendicke F, Frencken JE, Bjørndal L, Maltz M, Manton DJ, Ricketts D, Van Landuyt K, Banerjee A, Campus G, Doméjean S, Fontana M, Leal S, Lo E, Machiulskiene V, Schulte A, Splieth C, Zandona AF, Innes NP. Managing Carious Lesions: Consensus Recommendations on Carious Tissue Removal. Adv Dent Res. 2016; 28(2): 58-67. https://doi.org/10.1177/0022034516639271

18. Ismail AI, Tellez M, Pitts NB, Ekstrand KR, Ricketts D, Longbottom C, Eggertsson H, Deery C, Fisher J, Young DA, Featherstone JD, Evans W, Zeller GG, Zero D, Martignon S, Fontana M, Zandona A. Caries management pathways preserve dental tissues and promote oral health Community. Dent Oral Epidemiol. 2013; 41(1): 12-40. https://doi.org/10.1111/cdoe.12024

19. Marsh PD. Dental plaque as a microbial biofilm. Caries Res. 2004; 38(3): 204-11. $10.1159 / 000077756$. 
20. Fejerskov O. Changing paradigms in concepts on dental caries: consequences for oral health care. Caries Res. 2004; 38(3): 182-191. https://doi.org/10.1159/00007775

21. Selwitz RH, Ismail AI, Pitts NB. Dental caries. Lancet 2007; 369(9555): 51-59. https://doi.org/10.1016/S0140-6736(07)60031-2

22. Lederberg J. Of men and microbes. N Perspect Q. 2003; 20(3): 52-55.

23. Burne RA, Marquis RE. Alkali production by oral bacteria and protection against dental caries. FEMS Microbiol Lett 2000 Dec 1; 193(1): 1-6. https://doi.org/10.1111/j.15746968.2000.tb09393.x

24. Bardow A, Lagerlöf F, Nauntofte B, Tenovuo J. The role of saliva. En: Fejerskov O, Kidds E, editors. Dental caries. The disease and its clinical management. Oxford: Blackwell; 2008

25. Tanner ACR, Kressirer CA, Rothmiller S, Johansson I, Chalmers NI. The Caries Microbiome: Implications for Reversing Dysbiosis. Adv Dent Res. 2018 Feb; 29(1): 78-85. https://doi.org/10.1177/0022034517736496

26. Takahashi N, Nyvad B. The role of bacteria in the caries process: ecological perspectives. J Dent Res. 2011; 90(3): 294-303. https://doi.org/10.1177/0022034510379602

27. Reyes É, Martín J, Yevenes I, Neira M, Palma P, Gordan V, Moncada G. Actividad y efectos de ureasa y arginina deiminasa en saliva y biopelícula oral humana. Rev Fac Odontol Univ Antioq 2012; 23(2): 343-352

28. Dahlén G, Hassan H, Blomqvist S, Carlén A Rapid urease test (RUT) for evaluation of urease activity in oral bacteria in vitro and in supragingival dental plaque ex vivo. BMC Oral Health 2018; 18(1): 89. https://doi.org/10.1186/s12903-018-0541-3

29. Cagetti MG, Bontà G, Cocco F, Lingstrom P, Strohmenger L, Campus G. Are standardized caries risk assessment models effective in assessing actual caries status and future caries 
increment? A systematic review. BMC Oral Health. 2018; 18(1): 123. https://doi.org/10.1186/s12903-018-0585-4

30. Martignon S, Pitts NB, Goffin G, Mazevet M, Douglas GVA, Newton JT et al. CariesCare practice guide: consensus on evidence into practice. British Dental Journal. 2019 Sep 13; 227(5): 353-362. https://doi.org/10.1038/s41415-019-0678-8

31. Agencia Nacional de Evaluación de la Calidad y Acreditación. Libro blanco. Título de grado en odontología 2004. Madrid, España.

32. Federación Dental Internacional (FDI). El Desafío de las Enfermedades Bucodentales - Una llamada a la acción global. Atlas de Salud Bucodental. 2a ed. Ginebra, Suiza; 2015

33. Young DA, Nový BB, Zeller GG, Hale R, Hart TC, Truelove EL. American Dental Association Council on Scientific Affairs; American Dental Association Council on Scientific Affairs. The American Dental Association Caries Classification System for clinical practice: a report of the American Dental Association Council on Scientific Affairs. J Am Dent Assoc. 2015; 146(2): 79-86. https://doi.org/10.1016/j.adaj.2014.11.018

34. Zero DT. Sugars-the arch criminal? Caries Res 2004; 38(3): 277-285. https://doi.org/10.1159/000077767

35. Fontana M, Young DA, Wolff $\quad$ MS, Pitts $\quad$ NB, Longbottom $\quad$ C. Defining dental caries for 2010 and beyond. Dent Clin North Am. 2010; 54(3): 423-440. https://doi.org/10.1016/j.cden.2010.03.007

36. Pitts NB. Modern concepts of caries measurement. J Dent Res. 2004 ;83 Spec No C: C43-47. https://doi.org/10.1177/154405910408301s09

37. Kleinberg I. Studies on dental plaque. I. The effect of different concentrations of glucose on the $\mathrm{pH}$ of dental plaque in vivo. J Dent Res 1961; 40(6): 1087-1111 
38. Kleinberg I, Jenkins GN. The $\mathrm{pH}$ of dental plaques in the different areas of the mouth before and after meals and their relationship to the $\mathrm{pH}$ and rate of flow of resting saliva. Arch Oral Biol 1964; 9: 493-451. https://doi.org/10.1016/0003-9969(64)90015-9

39. Young DA, Lyon L, Azevedo S. The role of dental hygiene in caries management: a new paradigm. J Dent Hyg. 2010 Summer; 84(3): 121-129.

40. Llena C, Calabuig E. Risk factors associated with new caries lesions in permanent first molars in children: a 5-year historical cohort follow-up study. Clin Oral Investig. 2018 Apr; 22(3): 1579-1586. https://doi.org/10.1007/s00784-017-2253-5

41. Castellanos JE, Marín LM, Úsuga MV, Castiblanco GA, Martignon. La remineralización del esmalte bajo el entendimiento actual de la caries dental. Univ Odontol. 2013; 32(69): 49-59.

42. Signori C, Laske M, Bronkhorst EM, Huysmans MDNJM, Cenci MS, Opdam NJM. Impact of individual-risk factors on caries treatment performed by general dental practitioners J Dent. 2019; 81:85-90. https://doi.org/10.1016/j.jdent.2018.12.016

43. Kidd EA, Fejerskov O. What constitutes dental caries? Histopathology of carious enamel and dentin related to the action of cariogenic biofilm. J Dent Res. 2004; 83 Spec No C:C35-8. https://doi.org/10.1177/154405910408301s07

44. Petersen PE. The World Oral Health Report 2003: continuous improvement of oral health in the 21st century--the approach of the WHO Global Oral Health Programme. Community Dent Oral Epidemiol. 2003 Dec; 31(1): 3-23. https://doi.org/10.1046/j.2003.com122.x

45. Khalifah AM, Celenza A. Teaching and Assessment of Dentist-Patient Communication Skills: A Systematic Review to Identify Best-Evidence Methods. J Dent Educ. 2019; 83(1): 16-31. https://doi.org/10.21815/JDE.019.003 
46. Touger-Decker R, Van Loveren C. Sugars and dental caries. Am J Clin Nutr. 2003 Oct; 78(4): 881S-892S. https://doi.org/10.1093/ajen/78.4.881S .

47. van Loveren C. Sugar Restriction for Caries Prevention: Amount and Frequency. Which Is More Important? Caries Res. 2019; 53(2): 168-175. https://doi.org/10.1159/000489571

48. Sognnaes RF. Experimental rat caries; production of rat caries in the presence of all known nutritional essentials and in the absence of coarse food particles and the impact of mastication. J Nutr 1948; 36(1): 1-13. https://doi.org/10.1093/jn/36.1.1

49. Hendrik Meyer-Lueckel, Sebastian Paris, Kim Ekstrand. (2013) Caries Management - Science and Clinical Practice. Hamburgo, Alemania. $1^{\circ}$ ed. Thieme Publishing Group.

50. Walji MF, Karimbux NY, Spielman AI. Person-Centered Care: Opportunities and Challenges for Academic Dental Institutions and Programs. J Dent Educ. 2017; 81(11): 1265-1272. https://doi.org/10.21815/JDE.017.084

51. WHO (2015)? Guideline: sugars intake for adults and children. Geneva (Switzerland): World Health Organization.

52. Moynihan PJ and Kelly SA. Effect on caries of restricting sugars intake: systematic review to inform WHO guidelines. J Dent Res 2014; 93(1): 8-18. https://doi.org/10.1177/0022034513508954

53. Rozen R, Steinberg D, Bachrach G. Streptococcus mutans fructosyltransferase interactions with glucans. FEMS Microbiol Lett 2004; 232(1): 39-43. https://doi.org/10.1016/S0378$\underline{1097(04) 00065-5}$

54. Giacaman RA. Sugars and beyond. The role of sugars and the other nutrients and $\begin{array}{llll}\text { their potential impact on caries. } & \text { Oral } \quad \text { Dis. 2018; } & \text { 24(7): }\end{array}$ https://doi.org/10.1111/odi.12778 
55. Botelho JN, Villegas-Salinas M, Troncoso-Gajardo P, Giacaman RA and Cury JA. Enamel and dentine demineralization by a combination of starch and sucrose in a biofilm - caries model. Braz Oral Res 2016; 30(1): 1806-8324. https://doi.org/10.1590/1807-3107BOR2016.vol30.0052

56. Troncoso P, Botelho J, Villegas M, Giacaman R and Cury J (2011). Cariogenic potential of starch hydrolysates in enamel and dentin.: IV Latin American Region Meeting and XXIV Annual Meeting of the IADR Chilean Division. October 3, Santiago, Chile

57. Riley P, Moore D, Ahmed F, Sharif $\quad$ MO, Worthington $\quad$ HV. Xylitolcontaining products for preventing dental caries in children and adults. Cochrane Database Syst Rev. 2015; 26(3): CD010743. https://doi.org/10.1002/14651858.CD010743

58. Moynihan P. Foods and dietary factors that prevent dental caries. Quintessence Int 2007 Apr; 38 (4): $320-4$.

59. Williams KA, Schemehorn BR, McDonald JL Jr, Stookey GK, Katz S. Influence of selected fatty acids upon plaque formation and caries in the rat. Arch Oral Biol 1982; 27(12): 10271031. https://doi.org/10.1016/0003-9969(82)90007-3

60. Iida H, Auinger P, Billings RJ, Weitzman M. Association between infant breastfeeding and early childhood caries in the United States. Pediatrics 2007; 120(4): e944-e952. https://doi.org/10.1542/peds.2006-0124

61. Jenkins GN, Ferguson DB. Milk and dental caries. Br Dent J 1966; 120(10): 472-477

62. Palmer CA, Kent R Jr, Loo CY, Hughes CV, Stutius E, Pradhan N, Dahlan M, Kanasi E, Arevalo Vasquez SS, Tanner AC. Diet and caries Associated bacteria in severe early childhood caries. J Dent Res. 2010; 89(11): 1224-9. https://doi.org/10.1177/0022034510376543 
63. Bowen WH, Velez H, Aguila M, Velasquez H, Sierra LI, Gillespie G. The microbiology and biochemistry of plaque, saliva, and drinking water from two communities with contrasting levels of caries in Colombia, S.A. J Dent Res. 1977 Oct; 56 Spec No:C32-9. https://doi.org/10.1177/002203457705600314011

64. Rodríguez Sanz JR, Álvarez-Ude Cotera F, Cirera, J. M. Entrevista motivacional (parte I). FMC Formación Médica Continuada En Atención Primaria, 2014; 21: 9-24. https://doi.org/10.1016/s1134-2072(14)70778-9

65. Rodríguez Sanz J, Álvarez-Ude Cotera F, Cirera, J. M. Entrevista motivacional (parte II). FMC - Formación Médica Continuada En Atención Primaria, 2014; 21: 9-34. https://doi.org/10.1016/s1134-2072(14)70817-5

66. Michie S, van Stralen MM, West R. The behaviour change wheel: a new method for characterising and designing behaviour changeinterventions. Implement Sci. 2011 Apr; 23(6): 42. https://doi.org/10.1186/1748-5908-6-42

67. Pitts NB, Ekstrand KR. ICDAS Foundation. International Caries Detection and Assessment System (ICDAS) and its International Caries Classification and Management System (ICCMS) - methods for staging of the caries process and enabling dentists to manage caries. Community Dent Oral Epidemiol. 2013; 41(1): 41-52. https://doi.org/10.1111/cdoe.12025

68. Dikmen B. Icdas II criteria (international caries detection and assessment system). J Istanb Univ Fac Dent. 2015 Oct; 49(3): 63-72. https://doi.org/10.17096/jiufd.38691

69. Petersen PE. Sociobehavioural risk factors in dental caries -international perspectives. Community Dent Oral Epidemiol 2005; 33(4): 274-279. https://doi.org/10.1111/j.1600$\underline{0528.2005 .00235 . x}$ 
70. Sgan-Cohen HD, Evans RW, Whelton H, Villena RS, MacDougall M, Williams DM; IADRGOHIRA Steering and Task Groups. IADR Global Oral Health Inequalities Research Agenda (IADR-GOHIRAâ): a call to action. J Dent Res 2013; 92(3): 209-211. https://doi.org/10.1177/0022034512475214

71. Schwendicke F, Dörfer CE, Schlattmann P, Foster Page L, Thomson WM, Paris S. Socioeconomic inequality and caries: a systematic review and meta-analysis. J Dent Res. 2015 Jan; 94(1): 10-18. https://doi.org/10.1177/0022034514557546

72. Pitts N, Amaechi B, Niederman R, Acevedo AM, Vianna R, Ganss C, Ismail A, Honkala E .Global oral health inequalities: dental caries task group--research agenda. Adv Dent Res. 2011; 23(2): 211-220. https://doi.org/10.1177/0022034511402016

73. Guilbert JJ. The World Health Report 2006: working together for health. Educ Health (Abingdon). 2006; 19(3): 385-387.

74. Curnow MM, Pine CM, Burnside G, Nicholson JA, Chesters RK, Huntington E. A randomised controlled trial of the efficacy of supervised toothbrushing in high-caries-risk children. Caries Res. 2002; 36(4): 294-300. https://doi.org/10.1159/000063925

75. Marmot M, Bell R. Fair society, healthy lives. Public Health. 2012; 126(1): S4-S10. https://doi.org/10.1016/j.puhe.2012.05.014

76. Petersen PE Strengthening of oral health systems: oral health through primary health care. Med Princ Pract. 2014; 23(1): 3-9. https://doi.org/10.1159/000356937

77. Aristizabal M, Pava J, Lopez M, Aguilera S, Moreno G, Sanchez I, Escalante A, Duarte S, Lopez L, Garcia M, Garcia D, Jaramillo A, Aranzazu G. Care Perspectives of Periodontal Disease in Colombian Dental Schools. J Dent Res 2019. Res Vol \#98 (Spec Iss A): abstract number 1990. 
78. Gao XL, Hsu CY, Xu Y, Hwarng HB, Loh T, Koh D. Building caries risk assessment models for children. J Dent Res. 2010; 89(6): 637-43. https://doi.org/10.1177/0022034510364489

79. Fontana M, Zero D. Bridging the gap in caries management between research and practice through education: the Indiana University experience. Journal of dental education. 2007 May; 71(5): 579-591. 